\title{
Representações culturais no reality show gastronômico
}

\section{Cultural representations in the gastronomic reality show}

Karina Abdala ${ }^{1}$

Fernando Andacht ${ }^{2}$

Resumo: O artigo aborda a temática da representação cultural na mídia. O objetivo é compreender o sucesso de audiência de MasterChef partindo do pressuposto de que sua popularidade não pode ser explicada somente pelos aspectos gastronômicos envolvidos. Com esse objetivo, escolhemos para análise quatro programas do gênero híbrido talent show/reality show: a segunda temporada de La Comanda (2013), criada no Uruguai; a segunda de MasterChef Argentina (2015); as duas temporadas de MasterChef Uruguai (2017); e a quarta de MasterChef Brasil (2017). Com base numa abordagem qualitativa e comparativa, procuramos investigar as identidades coletivas de cada país conforme são construídas pela mídia. Para isso, adotamos uma metodologia sociossemiótica baseada nas noções analíticas de "imaginário social" e de gênero desses programas. Palavras-chave: representação cultural; imaginário social; MasterChef; reality show; talent show.

Abstract: The article focuses on cultural representation in the media. The goal is to understand the popularity of MasterChef; we claim that the attraction of the program is not based exclusively on its gastronomic aspects. For this aim, we have chosen to analyse four programs of the hybrid genre of talent show and reality show: the second season of La Comanda 2013, created in Uruguay; the second of

1 Universidad de la República (UdelaR). Montevidéu, Uruguai. https://orcid.org/0000-0002-3077-0810.E-mail: karina.abdala@fic.edu.uy

2 Universidad de la República (UdelaR). Montevidéu, Uruguai. https://orcid.org/0000-0003-3054-6090. E-mail: fernando.andacht@fic.edu.uy 
MasterChef Argentina 2015ç the two seasons of MasterChef Uruguay 2017; and the fourth of MasterChef Brazil 2017. By means of a qualitative and comparative approach, we study the collective identities of each country as they are constructed by the media. We use a socio-semiotic methodology; the analytical notions are the 'social imaginary' and the genre of the programs.

Keywords: cultural representation; social imaginary; MasterChef; reality show; talent show. 
Este artigo visa analisar as representações do "imaginário social" na mídia. Com esse objetivo, foram selecionados quatro programas de entretenimento televisual exibidos em três países - Argentina, Brasil e Uruguai -, quais sejam: MasterChef Argentina (doravante MCA); ${ }^{3}$ MasterChef Brasil (MCB); ${ }^{4}$ MasterChef Uruguai (MCU); ${ }^{5}$ e La Comanda $(L C),{ }^{6}$ produzido no Uruguai. As edições selecionadas correspondem às últimas temporadas exibidas em cada um dos países estudados no momento prévio à realização deste artigo. Foram analisados todos os episódios dos programas.

No que diz respeito à franquia MasterChef (doravante $M C$ ), os participantes devem preparar pratos culinários em aproximadamente 75 minutos e, para isso, precisam reunir os ingredientes - que estão disponíveis no mercado montado no próprio set do programa - em apenas três minutos.

No que concerne a $L C$, os participantes são estudantes de gastronomia da Universidade de Trabalho do Uruguai (UTU) ${ }^{7}$ e competem em equipes. Têm como desafio preparar cinco pratos correspondentes a um cardápio para cinco comensais, entre os quais estão incluídos os membros do júri, que são docentes da UTU. A diferença em relação a $M C$ é que os participantes contam com um dia para elaborar o cardápio, além de terem 30 minutos no mercado para escolher os ingredientes.

Consideramos importante compreender quais são os elementos que contribuíram para a geração do fenômeno do gênero reality show, que atualmente cumpre 20 anos na TV. Outrossim, parece relevante compreender algumas mudanças que o formato sofreu na sua etapa de amadurecimento. Em seu começo, o programa de maior sucesso foi o Big Brother. Conforme Corner (2002), esse formato já apresenta uma hibridação, que inclui aspectos de game show e talk show. Para explicar essa combinação, Corner (2002, p. 256) afirma que "Big Brother opera suas reivindicações do real dentro de uma

3 A segunda temporada, exibida em 2015, que tem 20 episódios.

4 A quarta temporada de MasterChef amadores, exibida em 2017, que tem 25 episódios.

5 As duas temporadas exibidas em 2017, ambas com 17 episódios.

6 A segunda temporada, exibida em 2013, que tem 18 episódios.

7 A Universidade de Trabalho do Uruguai é uma instituição de aprendizagem pública, científica e tecnológica fundada em Montevidéu. Seu funcionamento é semelhante ao do Senac no Brasil. 
artificialidade completamente controlada, na qual quase tudo que se poderia considerar verdadeiro do que as pessoas fazem e dizem [...] depende de elas estarem lá, perante as câmeras". Por sua parte, Hill (2014, p.116) sustenta que o gênero reality show apresenta como elemento central o drama, de forma que "essa tendência dramática estabeleceu o reality show como um gênero que funciona dentro de um quadro flexível da realidade". Atualmente, o formato deu uma virada muito grande com a introdução do requerimento de um conhecimento específico na área da cozinha. Nosso objetivo é descrever as características principais que explicam o sucesso de audiência, já que sempre existiram programas de gastronomia, todos focados na aprendizagem da elaboração dos pratos. Esses programas tradicionais de gastronomia só são assistidos por um nicho de audiência interessado em culinária. É nesse sentido que elaboramos uma abordagem sociossemiótica cuja base é a análise formal da experiência para aplicá-la aos programas selecionados.

Para compreender esse fenômeno, propomos a hipótese de que existem outros aspectos, além da gastronomia, que caracterizam os reality shows gastronômicos e que podem explicar a atração dos espectadores. Esses elementos se relacionam com as seguintes noções: imaginário social, verossimilhança e construção da autenticidade através das identidades dos vencedores dos programas.

Segundo Dyer, o conceito de "normalidade" na sociedade concorda com uma visão de mundo estabelecida pelo sistema de valores que os grupos dominantes pretendem salientar. "Essa visão de mundo é tão certa para grupos dominantes que eles fazem isso parecer (como parece para eles) 'natural' e 'inevitável' - e para todos - e, na medida do possível, estabelecem sua hegemonia” (DYER, 1984, p. 356).

Os programas selecionados pertencem ao gênero híbrido do reality e do talent show; esses elementos da estrutura "compõem a receita que mistura genuínas habilidades culinárias (talent) com o comportamento programado e esperável do gênero telerrealidade (reality)" (ANDACHT e MARQUIONI, 2016, p. 8). Nesses programas, há componentes distintivos que salientam como prevalente o aspecto reality, como a atitude do 
jurado na hora de comunicar sua avaliação, o "solilóquio" intermitente dos participantes e a narrativa sobre sua trajetória.

Além disso, segundo Hay e Ouellette, "o reality show governa menos através da disseminação da ideologia do que através da promulgação de jogos participativos e tutoriais de estilo de vida que orientam, testam e supostamente aprimoram a capacidade dos sujeitos de desempenhar um papel ativo" (HAY e OUELLETTE, 2008, p. 472). Com essas palavras, os autores tentam compreender a relevância da mistura dos gêneros dos programas.

Uma explicação para a popularidade ${ }^{8}$ da franquia $M C$ poderia ser, entre outros motivos, que "parece existir um fenômeno de moda relacionado à culinária e à gastronomia” (MARQUIONI e OLIVEIRA, 2015, p. 75). Além disso, esse sucesso de audiência também poderia ser explicado pelo conceito de imaginário social. Nesse sentido, os programas de reality gastronômico poderiam ser analisados como objetos midiáticos propícios para a representação de elementos constitutivos do imaginário social de uma comunidade.

Para compreender essa abordagem teórica, é necessário primeiro explicar a noção técnica de "imagem", que, na teoria semiótica, está caracterizada pela presença vaga, fugaz de uma "qualidade de sentimento" (PEIRCE, CP 5.44) que evocamos prazerosamente ou com desagrado. Trata-se de qualidades possíveis para os indivíduos pertencentes a uma mesma sociedade (ANDACHT, 1992, p. 15-17). Se levarmos em conta o modelo semiótico triádico de Peirce, que tem como fundamento a análise fenomenológica da experiência em apenas três categorias ou valências universais, as chamadas "categorias faneroscópicas" (CP 1.284), o conceito de imagem está associado ao universo da Primeiridade (CP 1.534), porque envolve inúmeras possibilidades através das quais os indivíduos conseguem imaginar algo mesmo que esse "algo" seja inexistente.

8 Conforme a nota do jornal uruguaio El Observador (25 de julho de 2017), o último programa da primeira temporada (2017) de MasterChef alcançou 21,2 pontos de audiência, um recorde no país.

9 As citas da obra de C. S. Peirce são feitas do modo habitual: CP [x.xxx] remete ao volume e ao parágrafo na edição de The Collected Papers of Charles S. Peirce. Todas as traduções são nossas. 
Nas ciências sociais, o termo imaginário social é usado para estabelecer os limites de tudo aquilo que qualquer pessoa pode considerar adequado ou não (TAYLOR, 2002; CASTORIADIS, 2013). Uma função do imaginário social é "decidir o que é o natural, a norma que rege nossa vida, em cada ocasião vital” (ANDACHT, 1992, p. 157). Na análise fenomenológica, a ideia de regra tem uma ligação com a categoria da Terceiridade, que se define como "a valência da dimensão geral da experiência” (CP 1.290), e, como tal, se identifica com as leis, com a regularidade do universo humano e cósmico: "o Terceiro é a Ideia do que é tal como ele é sendo um Terceiro, o Médio, entre um Segundo e seu Primeiro. Isto é, a Representação como um elemento do Fenômeno" (CP 5.66).

Adicionalmente, na análise dos programas, está presente a categoria fenomenológica da Segundidade, que pertence à ordem daquilo que é concretamente existente. Um exemplo pode ser retirado da composição dos jurados do formato MC. Nos programas observados, nos deparamos com três chefs de nacionalidades diversas. Se levarmos em conta o elemento gastronômico clássico e tradicional da boa cozinha, essa escolha deve ser verossímil, o que explicaria, por exemplo, a presença de um jurado francês. De todas as nacionalidades possíveis (Primeiridade), achamos no formato MC um fato concreto, a seleção factual de um chef da França (Segundidade), que usualmente é alguém que já mora no país da edição. Mas a tipologia ou dimensão convencional da origem francesa associada com o âmbito da gastronomia remete ao imaginário social enquanto uma regularidade cultural (Terceiridade); trata-se de uma regra não escrita que associa a França com a terra de onde provêm os melhores conhecedores e apreciadores da gastronomia.

Portanto, existem normas através das quais as sociedades estabelecem as atitudes em todos os campos de atividade como sendo aceitáveis ou não. No âmbito da interação pessoal, esse padrão remete ao conceito de "idealização" (GOFFMAN, 2012, p. 49), que diz respeito às formas como o sujeito sempre tentará se apresentar perante o outro do melhor modo possível. Por esse motivo, através de uma análise qualitativa e 
comparativa de um formato da televisão "glocal", o artigo visa estudar a representação de elementos de identidade cultural em diferentes países.

\section{A identidade como prato favorito de MC servido num solilóquio}

Um dos elementos centrais dos programas estudados é o uso do chamado "solilóquio". Esse recurso retórico permite um acesso à intimidade dos participantes: "em relação à confissão/revelação emocional, ela corresponde ao que se considera a típica função dramática do solilóquio de exibir emoções que estão à flor de pele" (ANDACHT e MARQUIONI, 2017, p. 9). Além disso, esse dispositivo serve como um guia para que o espectador compreenda o significado (supostamente) verdadeiro das atitudes dos participantes, de sua vida interior. O uso constante do solilóquio nos formatos apresenta "o reality show como uma ilustração da cultura confessional contemporânea em que a atração chave é a revelação das 'verdadeiras' emoções” (ASLAMA e PANTTI, 2006, p. 168). Em suma, a função principal desse recurso retórico e dramatúrgico utilizado de modo recorrente seria a produção de signos que permitiriam acessar a realidade última (ASLAMA e PANTTI, 2006, p. 175).

Se retomarmos as categorias com as quais Peirce analisa a experiência, uma das funções do solilóquio é produzir no espectador um sentimento vago de ter acesso à realidade última do indivíduo. Essa dimensão afetiva da comunicação corresponderia ao universo da Primeiridade.

O elemento primeiro (first) é predominante no sentimento (feeling), enquanto ele é diferente da percepção objetiva, da vontade e do pensamento (CP 1.302) Mas na medida em que a sensação é um mero sentimento de um tipo particular, ela está determinada só por um poder inexplicável e oculto; e nessa medida, ela não é uma representação, senão só a qualidade material de uma representação (CP 5.291).

Assim, esse dispositivo opera como um veículo plausível para a construção da apresentação da identidade de cada participante. Ele forma 
parte do Representamen, isto é, da dimensão sensorial do signo, daquilo que é perceptível em cada participante.

O solilóquio é utilizado de modo regular pelos participantes para exibir uma identidade. Esse comportamento tem como objetivo ser o vencedor do programa, de modo paralelo e simultâneo ao objetivo de se dar bem nas provas culinárias de cada semana. Do ponto de vista semiótico, a construção da identidade "implica uma harmonia teleológica nas ideias e, no caso da personalidade, é mais que uma mera procura deliberada de uma finalidade predeterminada; uma teleologia do desenvolvimento" (COLAPIETRO, 1989, p. 76). A noção teórica de "teleologia” implica uma organização das ações dos indivíduos que leva em conta a finalidade delas, embora esta possa não ser consciente.

Um exemplo disso pode ser observado em MCB, no começo da competição, nas provas por equipes, quando os participantes rejeitam a ideia de ter em seu grupo uma participante tailandesa de 31 anos de idade (Yukontorn). No quinto episódio, explica-se que os demais participantes acharam que Yukontorn não tinha conhecimentos próprios da gastronomia brasileira.

Outro exemplo pode ser observado na primeira temporada de $M C U$, quando a participante Lourdes, em sua forma de interatuar, se mostra como alguém muito forte e lutadora. No episódio 12, ela explicita sua finalidade: ela quer ganhar a competição, portanto não abre mão de uma rivalidade ostensiva. Além disso, ela se apresenta como uma fã da música rock e seus signos indiciais, materializados em suas reações corporais, revelam a característica de uma pessoa robusta e vigorosa. Até certo ponto, podemos fazer uma comparação com o juiz forte temido por todos, Enrique Fogaça, o jurado brasileiro de MCB, tal como mostram as Figuras 1 e 2. Ambas as presenças mostram a importância dos signos que revelam os aspectos próprios da individualidade, daquilo que é mais marcante e visível na personalidade de um sujeito. Esse efeito semiótico está baseado em uma mistura de elementos associados à categoria da Primeiridade - as qualidades de sentimento que podem ser extraídas pela análise (por exemplo, a qualidade de potência, pujança ou ímpeto) 
- com elementos associados à categoria da Segundidade - os elementos perceptíveis (por exemplo, o fato de ter tatuagens ou ser careca).

Figura 1: Lourdes, MCU, primeira temporada, episódio 1, 2017

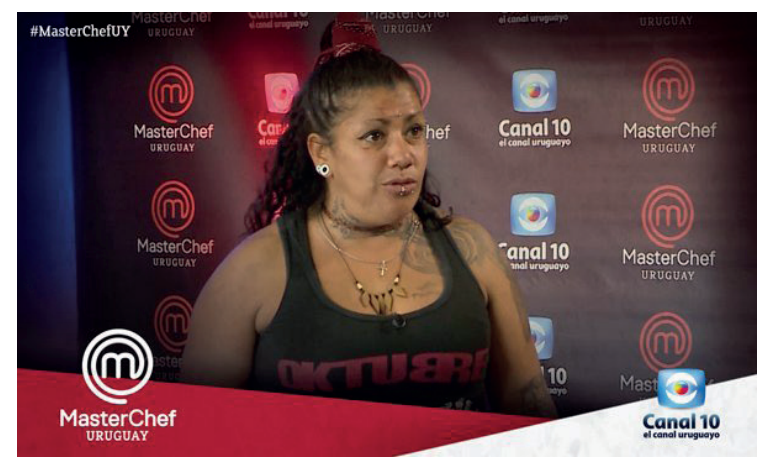

Fonte: arquivo do autor

Figura 2: Enrique Fogaça, MCB, quarta temporada, episódio 1, 2017

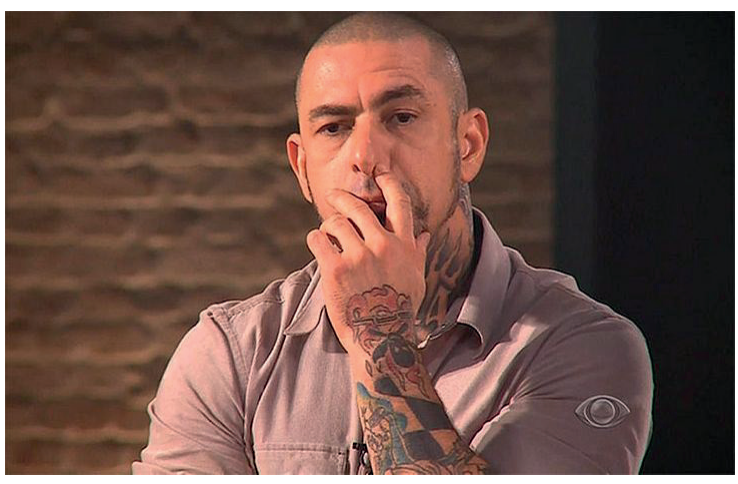

Fonte: arquivo do autor

Por outro lado, na primeira temporada de $M C U$, o participante Nilson desenvolveu uma identidade com caraterísticas divergentes. Ele sempre ajudava os outros participantes. Isso foi se tornando um rasgo de personalidade, uma identidade que foi exibida de modo inconsciente ou não, mas que não deixou de aparecer na tela e de ser interpretada como sua maneira de atuar no dia a dia. A finalidade aparente de 
Nilson, nesse caso, foi se apresentar da maneira mais humilde possível. Essa atitude pôde ser observada no episódio 16, quando ele disse: "Eu não compito contra Lourdes, eu compito contra mim mesmo".

Observamos na sequência de edições a emergência de identidades que se manifestam através da oposição mútua e que podem ser analisadas como representações de estereótipos que se associam ao imaginário de cada sociedade. Por exemplo, no caso uruguaio, os estudos midiáticos permitem postular que existe um imaginário que procura o estereótipo de humildade como tipo identitário idealizado, porém, obviamente, isso não implica que todos os uruguaios sejam assim. De acordo com Dyer (1984), existe nas sociedades um sistema de estereótipos sociais que funciona como uma espécie de limite da normalidade ou daquilo que é aceito como plausível ou aceitável num momento determinado: “Tipos são instâncias que indicam aqueles que vivem de acordo com as regras da sociedade (tipos sociais) e aqueles a quem as regras são delineadas para excluir (estereótipos). Por essa razão, os estereótipos também são mais rígidos que os tipos sociais" (DYER, 1984, p. 355).

De modo privilegiado, no caso dos reality shows gastronômicos estudados aqui, a estratégia retórica do solilóquio serve para mostrar e tematizar as mudanças que se desenvolvem nas identidades através das sucessivas edições do programa.

Embora os estereótipos moldem a representação da identidade nos reality shows, os indivíduos podem mudar seus objetivos devido à reflexão ou às atitudes dos outros participantes. Por esse motivo, para o desenvolvimento da identidade, é necessária a interpretação do outro (COLAPIETRO, 1989, p. 64). As tensões e alegrias no relacionamento entre os aspirantes ao prêmio do $M C$ são tão importantes quanto sua competência culinária.

A identidade considerada como signo:

É essencialmente temporal, não apenas ela é sempre incompleta, mas também é intrinsecamente irrealizável: Devido à duração finita da existência humana, ninguém dá conta plenamente de quem é. A pessoa é, até 
certo ponto, realizada no presente e, em muito maior grau, não realizada ao longo de sua vida (COLAPIETRO, 1989, p. 76).

Um exemplo do desenvolvimento da identidade acontece no episódio 9 de $M C B$, na partida de Caroline, uma participante de Barretos, 31 anos, pesquisadora de energia nuclear. A apresentadora se mostra triste porque Caroline faz piadas a respeito do medo que lhe produzia o jurado. Em seu solilóquio, no episódio 4, ela destacava que "é mais difícil MC que a física”. Nas despedidas, os participantes sempre lembram como foi o modo de se relacionar da pessoa que vai sair do programa com os outros, o que sublinha a centralidade do relacionamento e seus efeitos na apresentação de si mesmo.

\section{A vertiginem de MC e a morosidade de LC}

Em nosso corpus, o aspecto mais marcante no que diz respeito ao contraste entre MC e LC é a concepção da temporalidade: os participantes do primeiro formato devem enfrentar o tempo como desafio ou obstáculo mais formidável, já que os jurados exigem que se demonstre uma série de habilidades culinárias em muito pouco tempo. No mercado, eles têm apenas três minutos para obter os ingredientes necessários, então, irremediavelmente, se produz uma competição atlético-culinária que cumpre a função mais típica de um reality: a superação de obstáculos com evidente estresse dos participantes. No caso do segundo formato (LC), os participantes têm 30 minutos para obter os ingredientes no Mercado Agrícola de Montevidéu; ${ }^{10}$ trata-se, portanto, de um autêntico passeio pela sede do principal patrocinador. Desse modo, o programa consegue exibir os diversos locais de modo calmo e detalhado.

Em MCB, o componente temporal fica ainda mais explícito: no episódio 3, a jurada Paola Carosella, uma chef argentina, comenta: "O tempo é real, isso não é piada, ninguém vai parar o relógio por vocês”. No episódio 8, Abel, um competidor paraguaio de 31 anos, é expulso por não fazer o empratamento a tempo. Esses exemplos mostram a

10 Maior mercado agrícola do Uruguai, onde há produtos naturais e, em marioria, nacionais. 
obsessão e a angústia causadas pela manipulação da dimensão temporal de todas as ações do formato. É claro que, em outros gêneros televisivos que têm como prioridade a aprendizagem da cozinha, esse clima emocional não aparece porque é prejudicial para esse fim. No caso de $M C$, pelo contrário, a atitude rigorosa, inflexível do jurado gera um efeito de verossimilhança típico da narrativa do gênero reality - nesse caso, pelo uso dos prazos temporais rígidos e inexoráveis. Não é à toa que esse conceito da retórica clássica seja descrito como um "arsenal suspeito de procedimentos e de 'truques' que queriam fazer natural o discurso" (BARTHES et al., 1972, p. 14). A popularidade do programa pode ser considerada como um sintoma desse efeito fundamental de naturalização da artificialidade, que gera credibilidade e avaliação positiva do público de MC.

Outra diferença fundamental de estrutura entre MC e LC é que neste os participantes se dividem em equipes durante toda a competição. Esse trabalho em equipe, bem como o fato de os jurados serem também docentes dos participantes na sua formação fora do programa, parece estar relacionado com um fim didático mais marcado que no caso de $M C$. Um exemplo da prevalência do fim didático sobre a competição em LC pôde ser observado num incidente acontecido quando as brigadas deviam preparar o menu para cinco comensais com um orçamento de 1.500 pesos uruguaios (aproximadamente $\mathrm{R} \$ 180,00$ ). No episódio 12, a brigada (auto)denominada Les Piments decidiu comprar doces por um valor superior ao estipulado e, nesse momento, apareceu um aviso para o espectador explicando que a brigada desrespeitou as regras. Não obstante, não houve nenhuma sanção por parte dos jurados. Essas atitudes dos jurados/docentes aproximam bastante o formato LC de um talent show com evidentes fins didáticos e um nível de tolerância muito maior no que diz respeito à obediência das regras.

\section{Os jurados e os apresentadores dos programas analisados}

As intervenções dos jurados da franquia MC também servem para que os participantes construam suas identidades. Como já foi consignado, 
o solilóquio cumpre essa função, mas também o jurado faz um enquadramento dos papéis (GOFFMAN, 2012, p. 34) desenvolvidos pelos participantes. A função dos jurados é legitimar certas ações que são aceitas pela sociedade e que podem ser associadas com o conceito de “idealização" (GOFFMAN, 2012, p. 49). Portanto, seus comentários servem como uma espécie de guia para que os participantes aprendam o modo legítimo de atuar em determinadas situações. Há certas dicas dadas pelos jurados que, sem dúvida, excedem o âmbito culinário. Alguns conselhos visam provocar reações dos sujeitos. Essa finalidade faz parte da estrutura de $M C$ e se refere a um dos componentes centrais dos processos de significação que caracterizam o gênero reality show, os signos indiciais. Nas modalidades de comunicação descritas por Goffman na ordem da interação humana: "a expressividade do indivíduo (e, portanto, sua capacidade para produzir impressões) parece envolver dois tipos radicalmente distintos de atividade significante: a expressão que oferece e a expressão que emana dele" (GOFFMAN, 2012, p. 16). Em termos semióticos, nas expressões oferecidas por uma pessoa, prevalecem os símbolos. Em contrapartida, nas expressões que emanam de modo menos voluntário, no caso das reações corporais, prevalecem os índices.

Um exemplo representativo do comportamento expressivo de tipo indicial aconteceu no episódio 19 de MCB, quando Paola Carosella fez sua crítica a Alejandro, competidor de 22 anos nascido em Ribeirão Preto: "Falta humildade nesse bolo". O elemento indicial se manifesta nos gestos que acompanham esse comentário crítico. De modo quase idêntico, no episódio 12 de MCA, o chef-jurado francês Christophe Krywonis falou com dureza a Alejo, ${ }^{11}$ estudante de Marketing de 26 anos, e comentou o seguinte sobre o prato preparado por ele: "[O prato] consegue refletir tua personalidade, soberbo na apresentação, peca por soberba”. Além de descrever os desacertos do prato, essas críticas servem para que o espectador conheça a atitude que conforma e define a identidade de

11 No episódio 10, o competidor teve a possibilidade de se salvar de uma prova de eliminação, mas decidiu salvar outra competidora, assumindo caráter de herói. No episódio seguinte, fez um comentário que prejudicou o empratamento de outro participante; passou, então, de herói a vilão. 
cada competidor. A partir das atitudes pouco modestas do participante, as respostas dos jurados mostraram que a evolução gastronômica de Alejo, para além da aprendizagem em gastronomia, se transformou em uma aprendizagem de valores. Assim, o programa exibiu, junto com um gradual aprimoramento dos pratos do participante, os signos de um processo de desenvolvimento identitário.

Esses signos afastam o programa do componente talent show e o aproximam do gênero reality típico ou tradicional, como Big Brother. Em suma, através dos comentários concretos coletados aqui, fica explícita a intenção do jurado de estabelecer o papel de cada participante do modo mais espetacular possível. Também fornece uma evidência de que a identidade enquanto processo interpretativo dirigido ou manipulado pelo próprio formato está em constante desenvolvimento (COLAPIETRO, 1989, p. 66; CP 5.313).

A respeito dos jurados de $L C$, as críticas são muito mais leves do que as proporcionadas pelos já mencionados jurados de MCA. No caso de $L C$, o jurado sempre lembra às brigadas que elas devem pensar nos problemas como uma forma ótima de aprendizagem e que os erros são a melhor forma de se transformarem em cozinheiros melhores. Esse tipo de crítica é completamente diferente de alguns dos comentários feitos pelos jurados de $M C U$. No caso dos comentários do chef uruguaio Sergio Puglia, podemos observar que ele usa sempre frases que apontam para o elemento emocional, até mesmo melodramático, como, por exemplo, suas constantes referências ao fato de os pratos trazerem lembranças das famílias dos participantes ou da sua própria, lembranças que, com frequência, são acompanhadas por fartas lágrimas. As lágrimas exemplificam os signos associados a expressões que "emanam" do corpo (GOFFMAN), as que consideramos como uma das evidências ou signos indiciais mais persuasivos da autenticidade do gênero reality em todos os seus formatos. De maneira oposta, os jurados em LC procuram explicações racionais e completamente práticas, o que faz com que as críticas sejam leves e didáticas. 
Conforme Peirce (CP 1.530), existem três modalidades de relações: de comparação, de funcionamento e de pensamento. A relação de comparação corresponde ao universo da possibilidade, isto é, à categoria fenomenológica da Primeiridade. A relação de funcionamento se apresenta no caso dos fatos concretos e tangíveis, definidos como tudo aquilo que oferece resistência, que se manifesta a partir de um funcionamento de ação e reação que corresponde à categoria da Segundidade. Finalmente, temos as relações de pensamento, que correspondem ao âmbito dos conceitos e, portanto, pertencem à categoria da Terceiridade. Podemos dizer, então, que as críticas realizadas pelos jurados de LC correspondem às relações de pensamento. Nesse formato, procura-se também ressaltar as regras; trata-se de signos simbólicos, equivalentes às palavras, que são fruto da planificação dos indivíduos na sociedade.

No caso dos jurados de MC, através dos fragmentos apresentados anteriormente, podemos ressaltar também alguns aspectos que exemplificam as relações de comparação, pois o jurado faz uma analogia e uma rigorosa comparação entre todas as receitas preparadas por um participante até aquele momento na competição. Há também intenção de fazer uma distinção no que diz respeito às receitas preparadas pelos demais participantes. Tal comparação inclui, inevitavelmente, as apresentações pessoais, pequenas cenas autobiográficas. Dessas sequências de imagens emergem as qualidades que permitem extrair os elementos singulares da personalidade de cada participante.

Cabe salientar que as três relações lógicas que Peirce distingue estão presentes em todo momento, mas a estrutura de cada formato ou edição televisual faz prevalecer umas a outras. Nesses exemplos, embora os jurados de MC utilizem palavras (= pensamento) e imagens (= comparação), também é claro que eles procuram constantemente salientar os aspectos indiciais dos sujeitos, associados aos aspectos funcionais que, nos gêneros reality, atraem a atenção dos espectadores. Trata-se da chamada "transpiração sígnica" (ANDACHT, 2003, p. 43), conforme a seguinte definição do indicial de Peirce: 
Um índice é um signo que se refere ao Objeto que ele denota em virtude de ser realmente afetado por esse Objeto. Na medida em que o Índice é afetado pelo Objeto, ele necessariamente tem certa Qualidade em comum com o Objeto, e é com respeito a estas [qualidades] que se refere ao Objeto. Por conseguinte, envolve uma espécie de Ícone, embora seja um Ícone de um tipo peculiar; e não é a mera semelhança com seu Objeto, mesmo nestes aspectos, aquilo que o converte em um signo, senão que é sua modificação real pelo Objeto (CP 2.248).

Em relação à exibição de signos indiciais em $M C B$, no episódio 10 , o participante Vitor, curitibano de 26 anos, teve um acidente e cortou o dedo com uma faca. Depois, não pôde continuar cozinhando porque precisou de assistência médica, mas não quis sair da cozinha porque se lembrou do acontecido ao participante Abel. A alta tensão emocional da narrativa desse fato faz com que predominem no programa os aspectos que o aproximam do gênero reality show. Quando retornou à cozinha, Vitor, no seu solilóquio, destacou: "Eu me senti como no mito de Davi e Golias”, aumentando, assim, a atmosfera dramática do episódio.

Outro exemplo dessa busca por ressaltar os aspectos indiciais apareceu no episódio 3 da segunda temporada de $M C U$ a partir de uma forte crítica de Lucia Soria, a chef argentina, ao prato - nhoque, um tipo de alimento feito com massa branca - da participante Sandra, uma docente de 34 anos: "Isso parece dedinhos de gorila" (Figura 3). Pouco depois de receber essa opinião, Sandra quase desmaiou, seu corpo colapsou ante o olhar espantado de seus colegas. A reação corporal foi quase imediata, tudo aconteceu como se a opinião da chef tivesse derrubado a moça. Uma situação similar ocorreu no episódio 12 de MCB, quando Paola Carosella, chef argentina, disse à participante Miriam, paulista de 57 anos: "Isso parece uma barata quando você esmaga ela e sai o líquido" (Figura 4). 
Figura 3: Prato de Sandra, MCU, segunda temporada, episódio 3, 2017

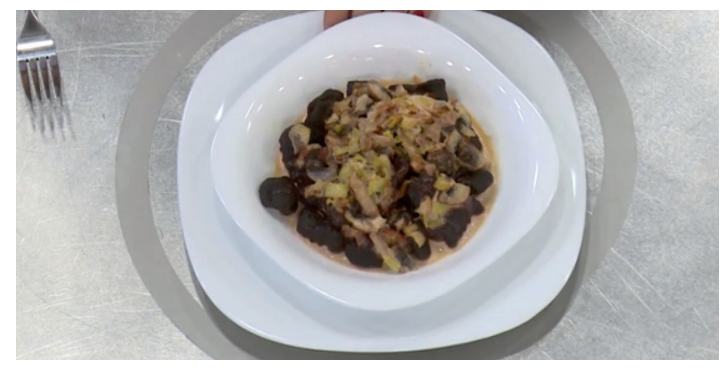

Fonte: arquivo do autor

Figura 4: Prato de Miriam, MCB, quarta temporada, episódio 12, 2017

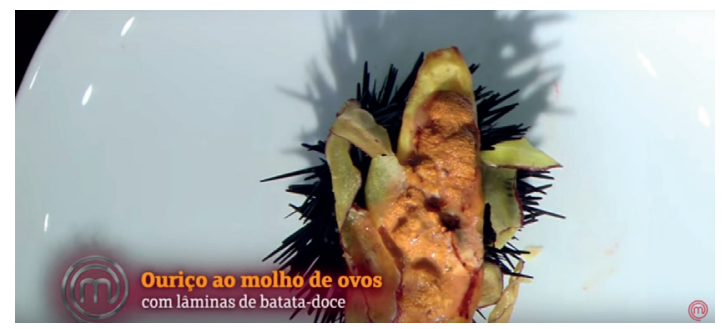

Fonte: arquivo do autor

A prevalência dos aspectos indiciais poderia, inclusive, ser considerada um elemento que justifica a comparação da franquia $M C$ com a pornografia. Trata-se de gêneros audiovisuais que enfatizam a experiência hiper-real de elementos corporais, de uma materialidade quase tangível, mas em ambos existe um marcante distanciamento entre o que se visualiza e as sensações físicas provocadas pelo visualizado (ANDACHT e MARQUIONI, 2016, p. 10-11). Isso poderia explicar o destaque e a exaltação de alguns signos indiciais por parte dos jurados quando procuram indicar para o espectador detalhes que remetem ao sabor, à textura e ao cheiro da comida preparada, elementos fundamentais na degustação do alimento que não são acessíveis ao espectador. Esses signos indiciais também são protagonistas no clímax narrativo de $M C$, ou seja, o desfecho de cada prova culinária. Em MCB, existe uma proeminência notável dos gestos na hora da avaliação dos pratos 
preparados, já que não é incomum que o jurado coloque a comida na boca dos participantes, procurando, assim, expressar, de modo hiperbólico, através das reações fisiológicas produzidas nos participantes, a experiência "direta" da comida, um simulacro sensorial que só pode ser contemplado e ouvido pelo espectador.

A respeito dos apresentadores das franquias $M C$, eles também procuram salientar aspectos indiciais associados não somente à comida, mas aos participantes, por meio de piadas ou comentários a respeito dos outros competidores. Um exemplo disso aparece nas provas por equipes, nas quais os capitães devem selecionar os integrantes dos grupos e os apresentadores perguntam o motivo de cada decisão. A participação dos apresentadores favorece, desse modo, o destaque do aspecto reality show do formato, pois, com suas intervenções, geram discussões entre os participantes, mitigando, assim, a importância da preparação de pratos culinários e salientando os aspectos identitários dos participantes.

Contrariamente, no caso do apresentador de $L C$, o jornalista esportivo Gonzalo Delgado sempre pede às brigadas a explicação de termos culinários, o que produz, novamente, um tipo de discurso que privilegia o componente simbólico-didático do formato. Não há dúvida de que a estrutura do programa uruguaio LC tem componentes que o aproximam mais do talent show que do reality show. Também cabe pensar em sua proximidade genérica com um tipo de programa de televisão didático que se ocupa, além do ensino da culinária, da promoção das virtudes do ensino público da profissão gastronômica pelo Estado, tarefa levada a cabo pela UTU.

\section{Aspectos culturais além dos pratos: os vencedores}

O estudo do corpus leva a concluir que os vencedores dos programas encarnam qualidades que estão associadas a estereótipos positivos e negativos dos países em que os shows são produzidos. O caso de Alejo, o vencedor do MCA, revela as atitudes e características de uma pessoa arrogante, alguém que se sentia seguro demais a respeito de todos os seus pratos e de sua inteligência e talento em geral. No caso de $M C B$, a vencedora Michele, 
de Santa Catarina, sempre se apresentou como uma mulher humilde, lutadora, que não era favorita para vencer o $M C$. Conforme a maioria das entrevistas que a apresentadora de $M C B$ fez, todos acreditavam que a vencedora seria Deborah, uma competidora de 30 anos do Rio de Janeiro, sua oponente na final. Novamente, na narrativa do programa, apareceu o mito de Davi e Golias, já que Deborah tinha as características de ser uma forte rival. Deborah sempre se mostrava muito segura na preparação das receitas e muitas vezes entregava o melhor prato, como no episódio 24. Porém, nesse mesmo episódio, o jurado Enrique Fogaça disse a ela: "Você é meio arrogante às vezes", após escutar as explicações da participante a respeito de seu prato.

No caso de $L C$ e da primeira temporada de $M C U$, os vencedores exibiram características similares às de Michele. A brigada de $L C$ que triunfou foi a que demostrou maior consistência entre sua apresentação, seus pratos e sua forma de trabalho. Nilson, o participante de 38 anos, o modesto policial nascido no interior do Uruguai, foi o primeiro vencedor de $M C U$. Ele tinha como virtude principal a humildade, algo que foi comentado positivamente por todos: Nilson ajudava os outros competidores e, sempre que possível, evitava o destaque excessivo. A humildade é uma qualidade muito valorizada na sociedade uruguaia; historicamente, é conhecida como a virtude mais característica da "mesocracia", um tipo de sociedade na qual se procura ter "condições de equilíbrio relativo e alta doses de conformidade social” (REAL DE AZÚA, 1964, p. 38). Portanto, as pessoas que desejam fazer parte dessa comunidade tentam não se vangloriar das qualidades positivas que consideram ter. Mas o que aconteceu com a vencedora da segunda temporada de MCU foi uma surpresa para a maioria dos uruguaios. Na final, a disputa aconteceu entre Luciana, uma educadora de Inau ${ }^{12}$ que já tinha participado na primeira temporada e sido eliminada do programa, e María Gracia, uma médica venezuelana de 29 anos. As caraterísticas identitárias atribuídas a Luciana, "simples, sensível, carinhosa", ${ }^{13}$ parecem materializar

12 Instituto da Criança e do Adolescente Uruguaio, que presta auxílio a menores infratores e cuida de crianças sem lar (equivalente à Febem no Brasil).

13 Ver https://www.canall0.com.uy/luciana-a2030. 
as qualidades quase ideais para encarnar mais uma vez o relato bíblico de Davi e Golias na sociedade mesocrática uruguaia.

Porém, quem venceu foi a venezuelana. Esse fato foi muito comentado pelos espectadores uruguaios nas redes sociais; houve, inclusive, um debate entre o público que expressava opiniões xenofóbicas a respeito da injustiça de um estrangeiro obter o prêmio que "deveria” ser dos nativos e os espectadores que se proclamavam a favor da imigrante e de sua integração à sociedade uruguaia. Na Figura 5, comentários recolhidos no site do jornal El Observador exemplificam essa intensa atividade nas redes sociais, em uma nota jornalística em que se descreve a vencedora da segunda temporada de $M C U$.

Figura 5: Comentários sobre o episódio final da segunda temporada de MCU nas redes sociais

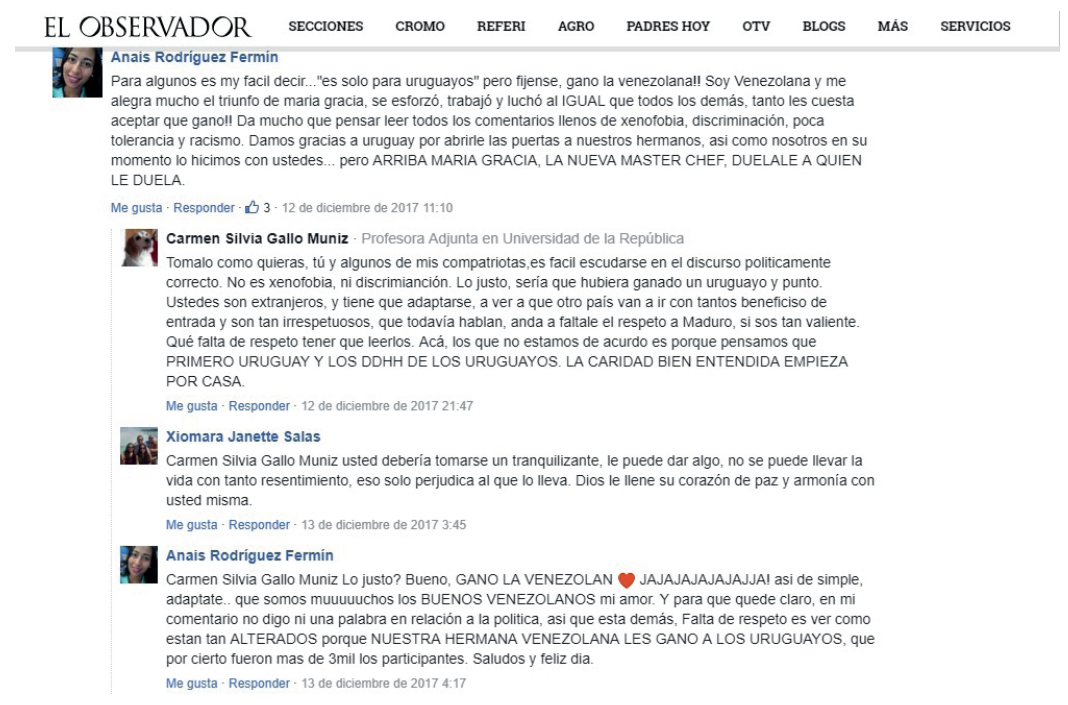

Fonte: El Observador, dezembro de 2017.

Com base nesses comentários, podemos postular a hipótese de que, apesar de sua origem estrangeira, a participante venezuelana conseguiu encarnar a personagem de Davi e encenar mais uma vez esse mito tão caro ao imaginário local. Ela apareceu como a representante de uma minoria em relação aos numerosos participantes uruguaios. 
Nesse caso, em nossa pesquisa, a noção de imaginário social se associa com o conceito do "glocal" (ANDACHT, 2003, p. 11), pois ambos os termos servem para explicar os aspectos culturais de tipo local que aparecem nas franquias televisuais, apesar de o formato ser mundial. Os exemplos de representações culturais podem ser observados não somente nas características pessoais dos vencedores dos programas, mas também na sua forte ligação com a gastronomia de cada país em que o formato é produzido. Isso é algo que os jurados ressaltam de modo evidente nas provas. No caso da primeira temporada de $M C U$, no episódio 2, o participante Gonzalo, um estudante de veterinária nascido no interior, preparou um prato com a forma de um chimarrão. Portanto, podemos dizer que o prato tinha uma relação icônico-indicial $(\mathrm{CP}$ 2.256) com um chimarrão, um dos objetos mais significativos da tradição local. Em seu solilóquio, ele comentou: "Eu fiz um simulacro de chimarrão, um dos bastões de cenoura, coloquei como um canudinho".

Figura 6: Prato de Gonzalo, MCU, primeira temporada, episódio 2, 2017

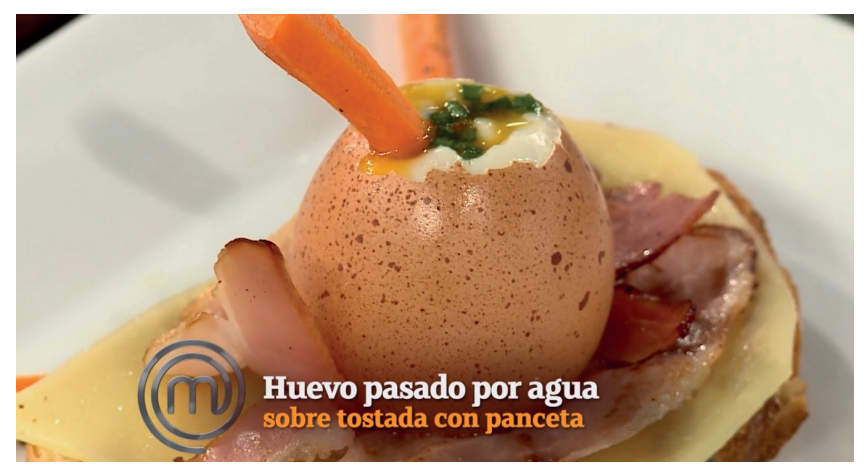

Fonte: arquivo do autor

Além da criação dos pratos, o elemento glocal se manifesta também em uma representação com predominância indicial quando os participantes são levados a lugares reconhecidos como emblemáticos da cultura uruguaia para preparar suas receitas. Além disso, no caso de $M C U$, na apresentação do programa, aparecem cartazes com a palavra "Uruguay" 
escrita com a cor celeste, que simboliza o país, especialmente no que diz respeito ao futebol (uma representação com predominância simbólica).

A respeito da noção de mesocracia, os valores associados a ela podem ser observados também nas atitudes da equipe vencedora de $L C$. Os participantes sempre destacaram sua crença no trabalho coletivo e em nenhum momento os grupos se mostraram convencidos de que iam ser os vencedores. No episódio final (número 18), em seus solilóquios, os membros da equipe (auto)denominada Magna expressavam: "É legal estar na final, acho que merecemos"; "Chegamos com esforço... com muito esforço"; "Agora temos uma chance em duas, eu acho que venceremos"; "Mas não há que se confiar”; “Tenho mais fé na equipe do que em mim mesmo". As falas, enunciadas por integrantes da equipe vencedora, mostram claramente a grande valoração da humildade, também presente nas atitudes do primeiro vencedor de $M C U$, Nilson. Pode-se estabelecer que a ideia de não sobressair está assentada no núcleo do conceito sociocultural e ideológico de mesocracia. No caso de $L C$, os integrantes da equipe vencedora permanecem em uma atitude de supressão do orgulho, de qualquer rastro de vaidade, uma tentativa extrema de se colocar num espaço mesurado, um meio-termo idealizado tradicionalmente pela nação uruguaia.

\section{Considerações finais}

O presente estudo consiste numa análise formal dos programas escolhidos que aplica as categorias da fenomenologia peirceana, que sustentam a definição de signo triádico, isto é, ícone, índice e símbolo, em vez de um estudo de recepção desses programas. Observamos que existe uma representação de aspectos culturais que é central para o significado dos programas de televisão investigados. Eles não somente remetem à produção de pratos reconhecidos como típicos da gastronomia de cada país em que se exibe a franquia MC. Além disso, esses programas operam como uma verdadeira vitrine social, na qual os componentes essenciais do imaginário social de cada comunidade são exibidos, destacados e legitimados. 
As referências gastronômicas locais estão presentes cada vez que os participantes devem preparar pratos em lugares reconhecidos como emblemáticos para a sociedade na qual o show é produzido. Através de diversos comportamentos, não apenas culinários, essas representações do imaginário social estão presentes e, o que é ainda mais importante para nossa análise, são exaltadas nas atitudes de cada aspirante a chef.

Os elementos constitutivos da estrutura dos programas, como o solilóquio dos participantes e o comportamento expressivo dos jurados, servem para guiar o espectador, para lhe indicar qual é o modo adequado de consumir esse formato. O funcionamento semiótico do programa orienta o público para que ele conheça em detalhe as identidades apresentadas pelos participantes, mais que os ingredientes e o método de preparar os pratos exibidos em MC. O resultado dessa estratégia retórica e narrativa é que o si mesmo desses homens e mulheres é encenado e exibido em um contínuo desenvolvimento. Essa estrutura faz com que o elemento gastronômico fique em segundo plano. Em vez de destacar os elementos que tipificam um talent show, finalmente aparecem como predominantes os elementos que definem e caracterizam o gênero reality show. Assim, os jurados tentam sempre levar os participantes a desempenhar os papéis mais adequados do ponto de vista emblemático ou representativo com respeito a seu país de origem. Guiado pelo roteiro do formato, através de comentários fortes, o jurado procura produzir reações físicas imediatas nos participantes. Assim, prevalecem os signos indiciais sobre os símbolos. Essa estratégia gera o efeito midiático e semiótico que chamamos de "transpiração sígnica" (ANDACHT, 2003, p. 43). Trata-se de signos inseparáveis do corpo dos participantes que aparecem como evidências de autenticidade e que operam como um "tempero" adicional e fundamental para o MC.

Por outro lado, nessa economia narrativa, o solilóquio contribui para salientar a dimensão identitária. Trata-se de uma classe de performance ou autoencenação que inevitavelmente reduz a importância do aspecto gastronômico que, supostamente, é o principal ingrediente do formato MC. O solilóquio tem a função de acalmar um problema ou crise gerando uma 
explicação possível, verossímil do acontecimento conforme o participante, especialmente quando há forte tensão com respeito à sua performance ou à sua interação com outros participantes. Isso faz com que a encenação dramatúrgica sirva para que os indivíduos trabalhem constantemente na elaboração e adaptação de seus papéis performáticos.

Se retomarmos as relações triádicas que Peirce (CP 1.530) chama de comparação, funcionamento e pensamento, conferimos que a estrutura da franquia $M C$ procura ressaltar as relações de comparação e de funcionamento; para que isso aconteça, são fundamentais o comportamento já descrito dos jurados e a presença recorrente do solilóquio como dispositivo retórico revelador da identidade dos participantes em seu relacionamento com os juízes e as outras pessoas no programa.

No caso de $L C$, as relações que prevalecem são as de "pensamento", porque sempre se busca estabelecer leis e definições didáticas dos elementos gastronômicos envolvidos para que os participantes consigam obter um bom conhecimento da área culinária. Esse elemento faz com que o programa se aproxime do gênero talent show.

O imaginário social se manifesta de modo explícito através das características dos vencedores dessa competição culinária. Por exemplo, Nilson, o vencedor da primeira temporada de $M C U$, encarna de modo paradigmático o morador típico da mesocracia uruguaia. Suas atitudes se aproximam desse ideal com tanta força que seu comportamento parece uma autêntica encarnação do estereótipo. A mesocracia enquanto ideal que regula comportamentos aparece como um componente central do imaginário social uruguaio, um princípio ético que parece ser ainda muito relevante para organizar os valores da população. Em suma, nos casos em que os vencedores são aceitos pelos espectadores, o perfil encenado por eles carrega traços identitários que delineiam os estereótipos prevalentes nos países respectivos. Inferimos, portanto, que os programas analisados cumprem a função de representar não somente os signos de uma gastronomia típica de cada região, mas também de apresentar determinados valores que estão em concordância com a cultura tradicional de cada lugar onde o programa é produzido. 


\section{Referências}

ANDACHT, F. El reality show: una perspectiva analítica de la televisión. Buenos Aires: Norma, 2003.

Signos reales del Uruguay imaginado. Montevidéu: Trilce, 1992.

.; MARQUIONI, C. Conversando com a comida: MasterChef e o solilóquio como acesso privilegiado à autenticidade. Famecos - Mídia, Cultura e Tecnologia. Porto Alegre: Universidade Católica do Rio Grande do Sul, v. 24, n. 2, 2017.

Jogando com a comida: MasterChef e os recursos televisuais que tornam espetacular uma atividade ordinária. E-compós, v. 19, n. 2, p. 1-16, 2016.

ASLAMA, M.; PANTTI, M. Talking alone: reality TV, emotions and authenticity. European Journal of Cultural Studies, v. 9, n. 2, p. 167-184, 2006.

BARTHES, R.; GENETTE, G.; KRISTEVA, J.; METZ, C.; MORIN, V.; TODOROV, T. Lo verosimil. Buenos Aires: Tiempo contemporâneo, 1968.

CASTORIADIS, C. La institución imaginaria de la sociedad. México: Tusquets Editores, 2013.

COLAPIETRO, V. Peirce's approach to the self. A semiotic perspective on human subjectivity. Albany: State University of New York Press, 1989.

CORNER, J. Performing the real. Television \& New Media, v. 3, n. 3, p. 255-269, 2002. DYER, R. Stereotyping. In: (Ed.). Gays and film. Nova York: Zoetrope, 1984. p. 353-365.

GOFFMAN, E. La presentación de la persona en la vida cotidiana. Buenos Aires: Amorrortu, 2012.

HAY, J.; OUELLETTE, L. Makeover television, governmentality and the good citizen. Continuum: Journal of Media \& Cultural Studies, v. 22, n. 4, p. 471-484, 2008.

HILL, A. Reality TV experiences: audiences, fact and fiction. In: OUELLETTE, L. (Ed.). A companion to reality television. Chichester, Reino Unido: John Wiley \& Sons, 2014. p. 116-133.

LA FINAL DE MASTERCHEF reventó los ratings com 21,2 puntos. El Observador, 25 jul. 2017. Disponível em: https://www.elobservador.com.uy/nota/la-final-de-masterchef-revento-los-ratings-con-21-2-puntos-201772510240. Acesso em: 7 mar. 2019.

MARQUIONI, C.; OLIVEIRA, C. Para além da competição: consumindo afetos como cultura material no programa MasterChef. Conexão. Caxias do Sul: UCS, v. 15, n. 28, 2015.

PEIRCE, C. S. The collected papers of C. S. Peirce. Ed. C. Hartshorne, P. Weiss e A. Burk. Cambridge: Harvard University Press, 1931-1958.

REAL DE AZÚA, C. El impulso y su freno. Montevidéu: Banda Oriental, 1964.

TAYLOR, C. Modern social imaginaries. Public Culture, v. 14, n. 1, p. 91-124, 2002. 


\section{Sobre os autores}

Karina Abdala - Licenciada em comunicação na UdelaR-FIC. Estudante do mestrado em Ciências Humanas, opção Antropologia, da Cuenca do Plata, UdelaR-FHUCE. Integra o grupo de pesquisa do projeto "Identidades do consumo. Imaginários e estilos de vida cultural no Uruguai contemporâneo" (UdelaR-FIC).

Fernando Andacht - Doutor em Filosofia pela University of Bergen, Noruega (1998). M. A. em Linguística pela Ohio University. Licenciatura em Letras na Facultad de Humanidades y Ciencias, Universidad de la República, Montevidéu. Bolsista Fulbright (1991) e da Fundação Alexander von Humboldt (1997-1998). Pesquisador Nível II, Sistema Nacional de Investigadores ANII/ Uruguai. Professor titular e coordenador do Departamento de Teoria \& Metodologia, Facultad de Información \& Comunicación, Universidad de la República, Montevidéu. Professor convidado do Programa de Pós-graduação em Comunicação e Linguagens da Universidade Tuiuti do Paraná, Curitiba. Foi professor e pesquisador na Universidade Federal do Rio Grande do Sul (2002-2003), na Unisinos (2004-2005), na University of Ottawa (2006-2015) e na Universidad Nacional de Córdoba (2007-).

Data de submissão: 09/03/2019

Data de aceite: 11/06/2019 